\title{
Analytical and Numerical Study of the Energy Spectrum of a Superlattice Consisting of Strips of Single-layer and Bilayer Graphene
}

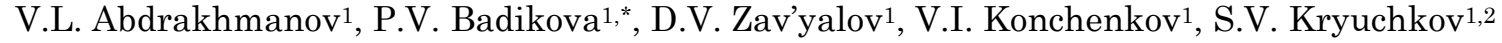 \\ ${ }^{1}$ Volgograd State Technical University, 28, Lenin Ave., 400005 Volgograd, Russia \\ ${ }^{2}$ Volgograd State Socio-Pedagogical University, 27, Lenin Ave., 400066 Volgograd, Russia
}

(Received 12 June 2020; revised manuscript received 18 December 2020; published online 25 December 2020)

\begin{abstract}
A model of a superlattice consisting of alternating strips of single-layer and bilayer graphene is proposed, whose parameters of the energy spectrum can be controlled by changing the external electric field perpendicular to the surface of the sample. Using the Kronig-Penney model, the dispersion equation is obtained based on the analysis of which the energy spectrum of a graphene superlattice is studied depending on the ratio of the strip widths of single-layer and bilayer graphene. For the considered superlattice, it is shown that there are two types of dispersion surfaces corresponding to two branches in the spectrum of bilayer graphene. In the absence of a transverse electric field, neighboring minibands obtained from the solution of different types of the dispersion equation touch at the edges of the first Brillouin band, and the conduction band and the valence band touch in the center of the first Brillouin band of the superlattice. The results of the analytical solution are compared with the results of modeling by methods of the density functional theory. It is shown that the low-energy approximation used to derive the dispersion equation is valid when considering a superlattice with narrow strips of bilayer graphene and wide strips of singlelayer graphene. Under this condition, the dispersion surfaces are symmetrical with respect to the K-point of the inverse space for the basic material - single-layer graphene. Quantum chemical modeling has shown that the band gap in the superlattice spectrum appears even in the absence of a transverse external field due to a violation of symmetry between states in different layers of bilayer graphene in the superlattice, and has confirmed the dependence of the band gap width on the transverse electric field.
\end{abstract}

Keywords: Bilayer graphene, Kronig-Penney model, Transfer matrix method, Methods of the density functional theory.

DOI: 10.21272/jnep.12(6).06029

PACS numbers: $72.80 . \mathrm{Vp}, 73.50 .-\mathrm{h}$

\section{INTRODUCTION}

The most important characteristic of lowdimensional semiconductor materials is the energy spectrum of charge carriers, in the first place, the width of the forbidden and allowed bands, as well as the shape and symmetry of dispersion surfaces. For example, the band gap determines the boundary frequency of the interminiband absorption of electromagnetic radiation. By varying the width of the gap, this effect can be used to determine the spectral composition of the incident radiation. It is promising to use various kinds of artificially created low-dimensional structures, the parameters of which can be changed both at the manufacturing stage, varying the chemical composition and sizes, and during direct measurements, applying to the sample as the basis for this kind of electromagnetic radiation detectors in the terahertz and far infrared ranges external fields. An example of such a structure is the graphene superlattice (GSL).

At the moment, a number of GSL models have been proposed [1-9], which differ in the way the additional periodic potential is formed. In works $[1,4,5]$, GSLs arising in graphene placed on a periodically modulated dielectric substrate were studied. The works $[2,6,7]$ are devoted to superlattices (SLs) formed in graphene under the action of an electric periodic or magnetic field in space. Moiré SLs are also known, which are formed when graphene layers are displaced by a small angle [3]. In addition to the effects expected for a GSL by analogy with other types of SLs, effects have recently been discovered that are not manifested in other materials, but due precisely to the two-dimensional nature of a GSL. So, in a recent work [3] it was shown that a transition to the superconducting state is observed in the moire SL. It is noted that such a structure can be used as a testing ground for studying high-temperature superconductivity.

A number of papers discuss the possibility of controlling the quantitative and qualitative parameters of the electronic energy spectrum of the GSL using external fields [4, 6-8]; in [10], a similar situation is studied in a single-layer modification of silicon - silicene. In [4], the manufacture and study of the transport properties of a SL formed in single-layer graphene placed over a substrate with a two-dimensional periodic structure of alternating holes in a dielectric under the influence of a constant electric field are described. The work [9] is devoted to the study of the electronic energy spectrum of SLs from alternating strips of single-layer and bilayer graphene based on the modified Kronig-Penney model. The case of the so-called unbias bilayer graphene is considered, that is the electron states on various graphene sheets are considered equivalent, and there is no gap in the energy spectrum. The GSL model considered in [9] is of interest, firstly, due to its relative simplicity, and secondly, due to the fact that when a transverse electric field is exposed to bilayer graphene, the symmetry between the layers is broken and a band gap is formed, therefore, the energy spectrum of the

\footnotetext{
*polin.badicova@gmail.com
} 
considered SL should also change. Since such a GSL consists of alternating strips of various materials, surface (Tamm) states should form at the boundaries of regions $[12,13]$. Due to the periodicity of localization of surface states, they form a zone of allowed energy values, which may have a different shape than the zones formed by the main periodic potential.

In a number of works, much attention is paid to the appearance of additional Dirac points and lines - points in the reciprocal space of the crystal lattice, in which the valence and conduction bands intersect, and charge carriers can be described as relativistic massless particles $[2,7]$.

Most studies of the energy spectrum of a GSL use the Kronig-Penney model, and only states near the K-point are taken into account. At the same time, in a SL consisting of strips of single-layer and bilayer graphene, not only low-energy states can influence the nature of the energy spectrum, therefore, independent verification of the results of model calculations is required, which can be carried out using quantumchemical methods.

In this work, an attempt is made to consider the electronic states in the GSL consisting of alternating strips of single-layer and bilayer graphene placed in a constant electric field perpendicular to the surface of the sample. It is expected that change in the electric field will make it possible to control the width of the forbidden and allowed minibands of the studied GSL, which in the future can be used to create electromagnetic radiation detectors. Fig. 1 shows the location of additional graphene strips forming bilayer regions. Here, $d_{I}$ and $d_{I I}$ are the strip widths of single-layer and bilayer graphene, respectively, $d$ is the period of the $\mathrm{SL}$. It is assumed that the bilayer regions are of type $\mathrm{AB}$ (the so-called Bernal stacking), the arrangement of atoms of the second layer of graphene relative to the first layer is shown in the insert. In Section 1, the energy spectrum of the considered GSL is studied analytically, and in Section 2, the results of quantum-chemical modeling by the methods of the density functional theory are presented. The work is a continuation of the studies begun in [14, 15]; a new one compared with [14] is the inclusion of Tamm states. The difference from [15] is a more detailed study of the shape of dispersion surfaces, in particular, the dependence of the energy in the minibands on the projection of the quasimomentum onto the direction perpendicular to the SL axis, and the conditions of applicability of the low-energy approximation in the Kronig-Penney model are clarified.

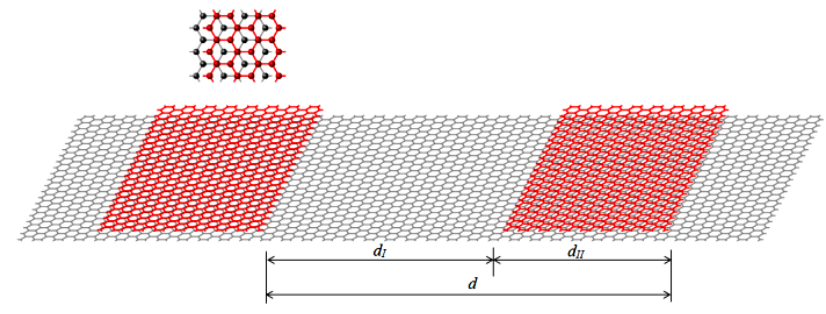

Fig. 1 - Layout of graphene strips forming bilayer regions on the main graphene sheet

$$
Q_{2}^{+}=\left(B^{2} q_{y}^{2}-\left(\Delta^{2}+E^{2}\right)+\sqrt{\left(4 \Delta^{2}+1\right) E^{2}-\Delta^{2}}\right) / B^{2},
$$

\section{THE DISPERSION EQUATION FOR A SUPER- LATTICE CONSISTING OF ALTERNATING STRIPS OF SINGLE-LAYER AND BILAYER GRAPHENE}

The energy spectrum of bilayer graphene, to which a transverse constant electric field is applied (the socalled bias bilayer graphene), is determined by the following expression [11]:

$$
\varepsilon_{\alpha}= \pm \sqrt{\Delta^{2}+\hbar^{2} v_{F}^{2} k^{2}+\frac{t_{\perp}^{2}}{2} \pm \sqrt{\hbar^{2} v_{F}^{2} k^{2}\left(4 \Delta^{2}+t_{\perp}^{2}\right)+\frac{t_{\perp}^{4}}{4}}} .
$$

Here, $v_{F} \sim 10^{8} \mathrm{~cm} / \mathrm{s}$ is the velocity on the Fermi surface in graphene, $\hbar k$ is the quasimomentum of the electron, $t_{\perp} \approx 0.4 \mathrm{eV}$ is the overlap integral between the layers of bilayer graphene, $\Delta \sim 0.1-0.3 t_{\perp}$ is a parameter that determines the band gap (half-width of the band gap $\left.\Delta^{\prime}=\Delta / \sqrt{4\left(\Delta / t_{\perp}\right)^{2}+1} \approx \Delta\right)$.

The dispersion relation is derived on the basis of the Kronig-Penney model using the T-matrix method $[1,16]$ and is considered in detail in [14].

The wave functions of the electron $\Psi_{I}$ in the region of single-layer and $\Psi_{I I}$ in the region of bilayer graphene can be represented as a four-component spinor:

$$
\Psi_{I, I I}=A\left(\left(\begin{array}{c}
\varphi_{1 p} \\
\varphi_{2 p} \\
\varphi_{3 p} \\
\varphi_{4 p}
\end{array}\right) \exp \left(i k_{I, I I} x\right)+\left(\begin{array}{c}
\varphi_{1 n} \\
\varphi_{2 n} \\
\varphi_{3 n} \\
\varphi_{4 n}
\end{array}\right) \exp \left(-i k_{I, I I} x\right)\right) \exp \left(i k_{y} y\right)
$$

The calculation shows that for the GSL under consideration there are two families of dispersion surfaces corresponding to the presence of two branches in the spectrum of bilayer graphene, which corresponds to two different expressions for $k_{I I}$ and two types of the dispersion equation. Both real and imaginary values of $k_{I I}$ in expression (2) should be considered, which was noted in [14]. In [14], a situation was considered when $k_{I}$ is a real number, but formally there is a solution of the dispersion equation for imaginary values of $k_{I}$, which indicates the formation of the so-called Tamm minibands that arise due to the periodic arrangement of surface states at the boundaries of single-layer and bilayer graphene regions. The inclusion of such states leads to two additional types of the dispersion equation.

The dispersion relation, which allows us to calculate the electron energy $E_{n}\left(k_{x}, k_{y}\right)$ ( $n$ is the miniband number, $k_{x}, k_{y}$ are the components of the electron quasimomentum) can be represented as:

$$
F\left(E, k_{I}(E), k_{I I}(E), k_{x}, k_{y}\right)=0 .
$$

Let us turn to dimensionless variables: $q_{x, y}=k_{x, y} d$, $q_{1,2}=k_{I, I I} d, \quad a_{I}=d_{I} / d, \quad a_{I I}=d_{I I} / d, \quad B=\hbar v_{F} /\left(t_{\perp} d\right)$. The values of $E$ and $\Delta$ will be measured in units of $t_{\perp}$. We introduce the following notations: 


$$
\begin{gathered}
Q_{2}^{-}=\left(B^{2} q_{y}^{2}-\left(\Delta^{2}+E^{2}\right)-\sqrt{\left(4 \Delta^{2}+1\right) E^{2}-\Delta^{2}}\right) / B^{2}, \\
Q_{1}=\left(E^{2}-B^{2} q_{y}^{2}\right) / B^{2} . \\
F_{1}=2 \cos q_{1} a_{I} \operatorname{ch} q_{2} a_{I I}+\frac{E^{2}\left(q_{1}^{2}-q_{2}^{2}\right)+\Delta^{2}\left(q_{y}^{2}-q_{1}^{2}\right)}{\left(\Delta^{2}-E^{2}\right) q_{1} q_{2}} \sin q_{1} a_{I} \operatorname{sh} q_{2} a_{I I}-2 \cos q_{x}, \\
F_{2}=2 \cos q_{1} a_{I} \cos q_{2} a_{I I}+\frac{E^{2}\left(q_{1}^{2}+q_{2}^{2}\right)+\Delta^{2}\left(q_{y}^{2}-q_{1}^{2}\right)}{\left(\Delta^{2}-E^{2}\right) q_{1} q_{2}} \sin q_{1} a_{I} \sin q_{2} a_{I I}-2 \cos q_{x}, \\
F_{3}=2 \operatorname{ch} q_{1} a_{I} \operatorname{ch} q_{2} a_{I I}+\frac{-E^{2}\left(q_{1}^{2}+q_{2}^{2}\right)+\Delta^{2}\left(q_{y}^{2}+q_{1}^{2}\right)}{\left(\Delta^{2}-E^{2}\right) q_{1} q_{2}} \operatorname{sh} q_{1} a_{I} \operatorname{sh} q_{2} a_{I I}-2 \cos q_{x}, \\
F_{4}=2 \operatorname{ch} q_{1} a_{I} \cos q_{2} a_{I I}+\frac{-E^{2}\left(q_{1}^{2}-q_{2}^{2}\right)+\Delta^{2}\left(q_{y}^{2}+q_{1}^{2}\right)}{\left(\Delta^{2}-E^{2}\right) q_{1} q_{2}} \operatorname{sh} q_{1} a_{I} \sin q_{2} a_{I I}-2 \cos q_{x} .
\end{gathered}
$$

The first family of surfaces can be obtained by solving the dispersion equation (3) with the following parameter values:

$$
\begin{aligned}
& Q_{1} \geq 0, Q_{2}^{+} \geq 0: q_{1}=\sqrt{Q_{1}}, q_{2}=\sqrt{Q_{2}^{+}}, F=F_{1} ; \\
& Q_{1} \geq 0, Q_{2}^{+}<0: q_{1}=\sqrt{Q_{1}}, q_{2}=\sqrt{-Q_{2}^{+}}, F=F_{2} ; \\
& Q_{1}<0, Q_{2}^{+} \geq 0: q_{1}=\sqrt{-Q_{1}}, q_{2}=\sqrt{Q_{2}^{+}}, F=F_{3} ; \\
& Q_{1}<0, Q_{2}^{+}<0: q_{1}=\sqrt{-Q_{1}}, q_{2}=\sqrt{-Q_{2}^{+}}, F=F_{4} ;
\end{aligned}
$$

The second family:

$$
\begin{aligned}
& Q_{1} \geq 0, Q_{2}^{-} \geq 0: q_{1}=\sqrt{Q_{1}}, q_{2}=\sqrt{Q_{2}^{-}}, F=F_{1} \\
& Q_{1} \geq 0, Q_{2}^{-}<0: q_{1}=\sqrt{Q_{1}}, q_{2}=\sqrt{-Q_{2}^{-}}, F=F_{2} ; \\
& Q_{1}<0, Q_{2}^{-} \geq 0: q_{1}=\sqrt{-Q_{1}}, q_{2}=\sqrt{Q_{2}^{-}}, F=F_{3} ; \\
& Q_{1}<0, Q_{2}^{-}<0: q_{1}=\sqrt{-Q_{1}}, q_{2}=\sqrt{-Q_{2}^{-}}, F=F_{4}
\end{aligned}
$$

The dispersion equations were solved numerically by the Newton method.

Fig. 2 shows the four bottom minibands, the arrangement of which corresponds to the conduction band of the basic material (the case is considered when the strip width of bilayer graphene is much larger than the strip width of single-layer graphene $\left(a_{I}=0.05, a_{I I}=0.95\right.$, value $\Delta=0.1$ in units of $t_{\perp}$ ). The two lower minibands are determined by the solution of the dispersion equation in the form (12), the two upper minibands - in the form (11). It is seen that in the situation under consideration, energy gaps appearing between minibands are significant, i.e., the structure under consideration must have the properties of a semiconductor. The energy spectrum is periodic in $q_{x}$.

It should be noted that the shape of the dispersion surfaces corresponding to different families differs significantly in the case of wide strips of bilayer and narrow strips of single-layer graphene. In the opposite case, the considered families of dispersion surfaces have a similar shape, but are spaced a small distance in energy. Fig. 3 shows the dispersion lines constructed for the case $a_{I}=0.95, a_{I I}=0.05$ and $\Delta=0$. The solid line indicates the dispersion curves described by expressions (11), the dashed line indicates the curves described by expressions (12).

It can be seen that the upper miniband of the family described by expressions (12) intersects with the lower miniband of the family described by expressions (11) at values $q_{x}= \pm \pi$, i.e., the so-called Dirac lines are present in the energy spectrum of the studied GSL. At $\Delta \rightarrow 0$, the minimum value of energy in the lowest mini-band described by expressions (12), located at a point $\left\{q_{x}, q_{y}\right\}=\{0,0\}$, is zero, that is, the conduction band and the valence band of the considered GSL touch at this point, which is a characteristic feature of singlelayer and bilayer graphene in the absence of an external transverse electric field.

Thus, using the T-matrix method, dispersion relations are obtained that describe two families of dispersion surfaces. The obtained GSL energy spectrum has a miniband character, and the width of the energy gaps between the minibands strongly depends on the ratio of the well width to the barrier. It is significant that along with the solutions of the Schrödinger equation oscillating in the well region, there are the decay solutions in the well region, corresponding to the Tamm states.

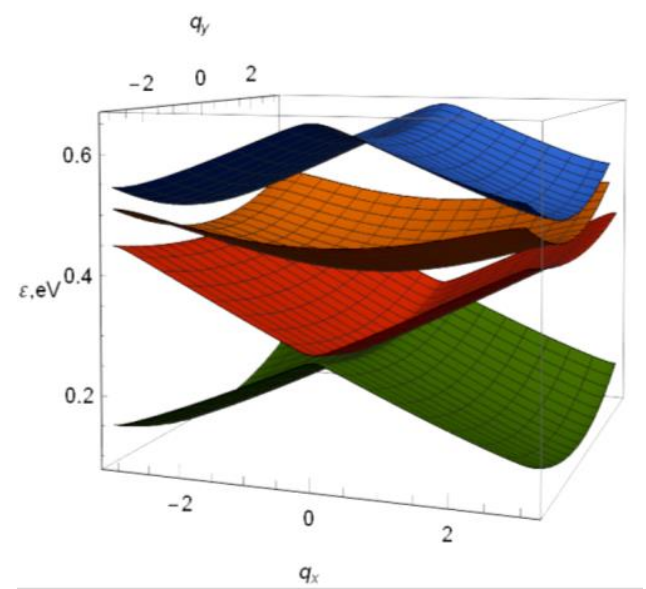

Fig. 2-Dispersion surfaces of charge carriers at $\Delta=0.1$, $a_{I}=0.05, a_{I I}=0.95$ 


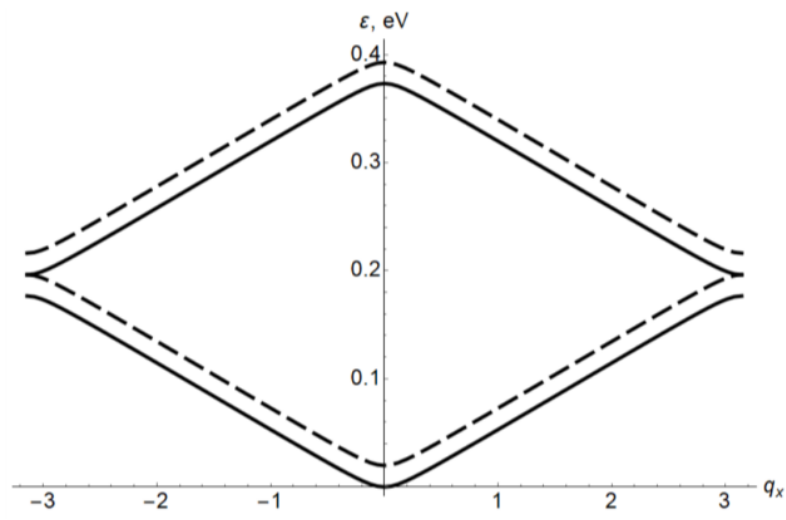

Fig. 3 - Dispersion curves plotted for case $\Delta=0, q_{y}=0, a_{I}=0.95$, $a_{I I}=0.05$

\section{QUANTUM-CHEMICAL MODELING OF THE ENERGY SPECTRUM}

The study of the energy spectrum of the GSL considered above was conducted using the OpenMX package. OpenMX (Open source package for Material eXplorer) is a software package for nanoscale material simulations based on density functional theory (DFT), norm-conserving pseudopotentials, and pseudoatomic localized basis functions. This allows us to more efficiently calculate properties of periodic systems consisting of hundreds and thousands of atoms with less time costs than plane wave based ones. The methods and algorithms used in OpenMX and their implementation are carefully designed for the realization of large-scale $\mathrm{ab}$ initio electronic structure calculations on parallel computers. The calculations were performed for a SL with a period $d=10.9 \mathrm{~nm}$, which corresponds to the 51 period of the main graphene lattice, with a variable width of the second layer. During the SCF calculation, a PBE functional was used, and integration over the Brillouin zone was performed on a regular $4 \times 16$ grid. The accuracy of the calculation was $10^{-6}$ hartree.

The crystal lattice of graphene is a hexagonal lattice whose constant is $a_{0}=2.46 \AA$. The primitive graphene cell includes 2 atoms located in the plane of the lattice. The lattice parameters of single-layer graphene coincide with the parameters of the primitive lattice of bilayer graphene, consisting of 4 atoms [11]. We consider bilayer graphene of type AB (Bernal stacking graphene, see Fig. 1). In both single-layer and bilayer graphene, the minimum of the conduction band is located at the K-point of the Brillouin zone. Strips of single-layer and bilayer graphene in the considered superlattice alternate in the direction of the $\mathrm{X}$-axis. The values of the quasi-wave vectors are counted from the K-point.

The simulation showed, first, that the minibands forming the Dirac cone are shifted to the high-energy region by about $0.1 \mathrm{eV}$, and even in the absence of a transverse electric field, a band gap is formed. Second, the energy spectrum of the studied GSL is periodic in the direction of alternating layers and is even in $q_{x}$ (Fig. 4), and this result is valid for all relative widths of stripes of single-layer and bilayer graphene. Third, the energy spectrum becomes asymmetric in $q_{y}$ as the ratio of the strip width of bilayer graphene to the period of the SL increases. This result can be explained in the following way. When the strip width of bilayer graphene is small compared to the SL period, we can consider the carbon atoms in the second graphene layer as regularly located impurities of high concentration, which explains the energy shift of the position of the Dirac point. On the other hand, the periodicity of the location of such an "impurity" leads to the formation of minibands, which, due to the large difference between the SL period and the crystal lattice period of the base material (single-layer graphene), do not have to be symmetrical about the $\mathrm{K}$ point. As can be seen from Fig. 5, for a small relative strip width of bilayer graphene $\left(d_{I I} / d=3 / 51\right)$, the asymmetry of the dispersion curves in $q_{y}$ is small, therefore, under such conditions, the low-energy approximation used in Section 1 for the analytical consideration of the properties of SLs can be considered justified.

It should be noted that under the assumption that the strips of bilayer graphene are narrower than the strips of single-layer graphene, the considered SL turns out to be ideologically close to one of the first GSL models proposed in [17]. In [17], a GSL formed in single-layer graphene as a result of the deposition of periodically arranged lines of hydrogen atoms on it was considered.

The GSL considered in this work has forbidden and allowed miniband widths of the order of hundreds of electron-volts, and these parameters can be controlled by applying an external electric field perpendicular to the surface of the sample.

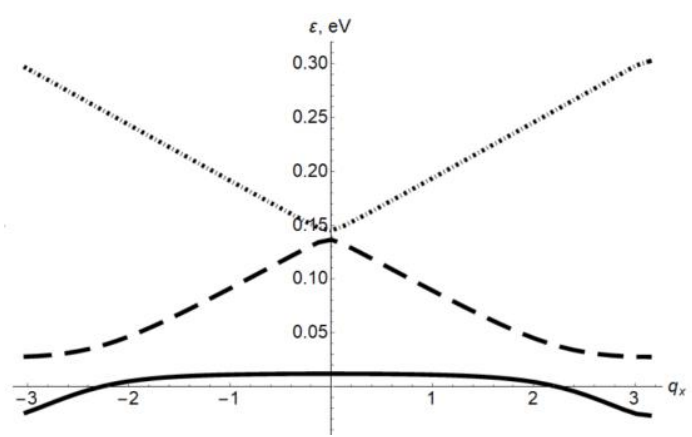

Fig. 4 - Dependence of the electron energy on the projection of the quasimomentum in the direction of the axis of the SL, in minibands closest to the Dirac point in the graphene spectrum, in case $d_{I I} / d=3 / 51\left(q_{y}=0\right)$

\section{CONCLUSIONS}

Using the analytical approach and quantumchemical modeling, the electronic states in the GSL, consisting of alternating strips of single-layer and bilayer graphene, placed in a constant electric field perpendicular to the surface of the sample, are investigated. It is shown that the energy spectrum of the structure under consideration has a miniband character, the widths of the forbidden and allowed minibands are hundreds of electron-volts and can be controlled by an external electric field.

For analytical consideration, the Kronig-Penney model was used. Dispersion equations of two types were obtained, corresponding to two branches in the energy spectrum of bilayer graphene, and each type of dispersion equation also describes the states corresponding to Tamm minibands. 


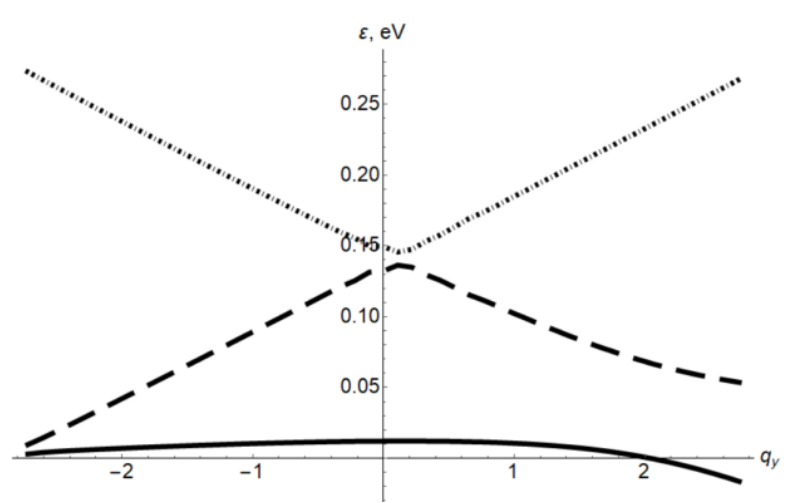

Fig. 5 - Dependence of the electron energy on the projection of the quasimomentum in the direction perpendicular to the axis of the SL, in minibands closest to the Dirac point in the graphene spectrum, in case $d_{I I} / d=3 / 51\left(q_{x}=0\right)$

\section{REFERENCES}

1. P.V. Ratnikov, JETP Lett. 90, 469 (2009).

2. M. Barbier, P. Vasilopoulos, F.M. Peeters, Phys. Rev. B 81, 075438 (2010).

3. G. Chen, A.L. Sharpe, P. Gallagher, I.T. Rosen, E.J. Fox, L. Jiang, B. Lyu, H. Li, K. Watanabe, T. Taniguchi, J. Jung, Z. Shi, D. Goldhaber-Gordon, Y. Zhang, F. Wang, Nature 572, 215 (2019).

4. C. Forsythe, X. Zhou, K. Watanabe, T. Taniguchi, A. Pasupathy, P. Moon, M. Koshino, P. Kim, CR. Dean, Nature Nanotech 13, 566 (2018).

5. S.V. Kryuchkov, C.A. Popov, J. Nano- Electron. Phys. 9 No 2, 02013 (2017).

6. D. Dragoman, M. Dragoman, R. Plana, J. Appl. Phys. 107, $044312(2010)$

7. S. Dubey, V. Singh, A.K. Bhat, P. Parikh, S. Grover, R. Sensarma, V. Tripathi, K. Sengupta, M.M. Deshmukh, Nano Lett. 13, 3990 (2013).

8. D.M. Hoat, M. Naseri, R. Ponce-Perez, N.N. Hieu, T.V. Vu, J.F. Rivas-Silva, G.H. Cocoletzi, Superlattice. Microst. 137, 106357 (2020).
The energy spectrum of the considered GSL was simulated using the methods of the density functional theory implemented in the OpenMX package. Based on quantum-chemical modeling, it was shown that the results of an analytical review regarding the conclusions about the existence of a miniband spectrum, symmetric with respect to the K-point of the starting material, single-layer graphene, are valid in the case of SLs composed of wide strips of single-layer and narrow bands of bilayer graphene. In other cases, the energy spectrum of the SL is not symmetric with respect to the $\mathrm{K}$-point in the direction perpendicular to the SL.

\section{ACKNOWLEDGEMENTS}

This work was financially supported by the grant of the Russian Foundation for Basic Research and the Administration of Volgograd Region as part of a scientific project 19-42-343006 r_mol_a.

9. X. Fan, W. Huang, T. Ma, L.-G. Wang, H.-Q. Lin, EPL 112, 58003 (2015).

10. C.-H. Chen, W.-W. Li, Y.-M. Chang, C.-Y. Lin, S.-H. Yang, Y. Xu, Y.-F. Lin, Phys. Rev. Appl. 10, 044047 (2018).

11. A.V. Rozhkov, A.O. Sboychakov, A.L. Rakhmanov, F. Nori, Phys. Rep. 648, 1 (2016).

12. P.L. Pekh, A.P. Silin, Phys. Wave Phen. 25, 249 (2017).

13. S.G. Tikhodeev, Solid State Commun. 78, 339 (1991).

14. V.I. Konchenkov, D.V. Zavay'lov, S.V. Kryuchkov, 2017 IEEE 7th International Conference Nanomaterials: Application \& Properties (NAP), 04NESP15 (2017).

15. V.L. Abdrakhmanov, D.V. Zavay'lov, S.V. Kryuchkov, 2017 IEEE 7th International Conference Nanomaterials: Application \& Properties (NAP), 03CBN11 (2017).

16. C.H. Pham, H.C. Nguyen, V.L. Nguyen, J. Phys.: Condens. Mat. 22, 425501 (2010).

17. L.A. Chernozatonskiı̌, P.B. Sorokin, E.É. Belova, J. Brüning, A.S. Fedorov, JETP Lett. 85, 77 (2007).

\title{
Аналітичне та чисельне вивчення енергетичного спектру надрешітки, що складається із смуг одношарового та двошарового графена
}

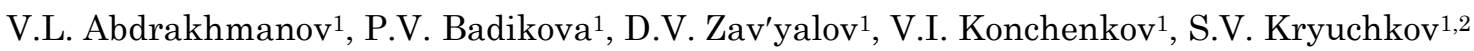 \\ 1 Volgograd State Technical University, 28, Lenin Ave., 400005 Volgograd, Russia \\ ${ }^{2}$ Volgograd State Socio-Pedagogical University, 27, Lenin Ave., 400066, Volgograd, Russia
}

\begin{abstract}
Запропонована модель надрешітки, що складаеться почергово із смуг одношарового та двошарового графена, параметри енергетичного спектру якого можна контролювати, змінюючи зовнішне електричне поле, прикладене перпендикулярно поверхні зразка. За допомогою моделі Кроніга-Пенні отримано дисперсійне рівняння, на основі аналізу якого вивчається енергетичний спектр графенової надрешітки залежно від співвідношення ширини смуг одношарового та двошарового графена. Для розглянутої надрешітки показано, що існуе два типи дисперсійних поверхонь, які відповідають двом гілкам у спектрі двошарового графена. За відсутності поперечного електричного поля сусідні мінісмуги, отримані з розв'язку різних типів дисперсійного рівняння, стикаються по краях першої зони Бріллюена, а зона провідності та валентна зона стикаються в центрі першої зони Бріллюена надрешітки. Результати аналітичного розв'язку порівнюються з результатами моделювання методами теорії функціоналу густини. Показано, що низькоенергетичне наближення, яке використовуеться для отримання дисперсійного рівняння, справедливо при розгляді надрешітки з вузькими смугами двошарового градена та широкими смугами одношарового графена. За цієї умови дисперсійні поверхні симетричні відносно точки K у оберненому просторі для вихідного матеріалу - одношарового графена. Квантово-хімічне моделювання показало, що заборонена зона в спектрі надрешітки виникае навіть за відсутності поперечного зовнішнього поля через порушення симетрії між станами в різних шарах двошарового графену в надрешітці, і підтвердило залежність ширини забороненої зони від поперечного електричного поля.
\end{abstract}

Ключові слова: Двошаровий графен, Модель Кроніга-Пенні, Метод матриці переносу, Методи теорії функціоналу густини. 